\title{
Rios e governos no Estado do Paraná pontes, "força hydraúlica" e a era das barragens (1853-1940)*
}

\section{Rivers and governments in the State of Paraná bridges, 'hydraulic force' and the era of the dams (1853-1940)}

GILMAR ARRUDA

Dep. História/Universidade Estadual de Londrina Rua Olavo Bilac, 426, apto 33,J d. Champagnat Londrina-PR - 86062-260 arruda@sercomtel.com.br

RESUMO Utilizando principalmente as Mensagens e Relatórios Presidenciais da Província e do Estado do Paraná como fontes documentais, busca-se examinar como os rios do território paranaense apareceram nas ações dos governantes do Estado entre 1854 e a década de 1940. Em determinadas ações os rios assumiram grande visibilidade, vistos como caminhos ou como "força hydráulica", em outras desaparecem atrás das técnicas utilizadas para a transposição, como as balsas e pontes. As pontes ou as barragens são momentos específicos da história das relações do homem com a natureza, indicando as formas de apropriação desse elemento natural pela sociedade.

Palavras-chave História Ambiental, História dos rios, territórios, era das barragens

* Artigo recebido em: 20/08/2007. Aprovado em 10/12/2007. 
ABSTRACT By using mainly the Presidential Annual Reports of the Province and the State of Paraná as documental sources, this work aims at examining how the rivers in the Paraná area are mentioned in the State governors' actions between 1854 and the 1940's. In some actions the rivers had great visibility, seen as ways or "hydraulic force"; in others, they completely disappear behind transposition techniques, like ferry-boats and bridges. The bridges or dams are specific moments in the history of the relationship between man and nature, indicating the ways of appropriation of such a natural element by the society.

Keywords Environmental History, History of rivers, territories, the era of the dams

\section{Introdução}

As Mensagens dos Presidentes de Província e do Estado são documentos que contemplam amplas possibilidades de estudos históricos, incluindo o campo da história ambiental. As séries históricas, em geral, possuem poucas lacunas; têm estrutura semelhante ao longo dos anos, permitindo comparações; frequentemente trazem anexos relatórios de engenheiros, botânicos, médicos e outros profissionais em expedições ao interior do território, com descrições detalhadas de paisagens, rios, florestas, populações, etc; encontra-se, também, mapas cartográficos do território, projetos de estradas, ferrovias, prédios públicos, etc. Além dessas características, foram microfilmados pela Biblioteca Nacional e, agora, estão disponíveis na rede mundial de computadores. ${ }^{1}$

No Paraná, antiga Quinta Comarca da Província de São Paulo, transformado em província em 1853, com extenso território recoberto por densas florestas, com população branca restrita ao litoral, arredores de Curitiba e ao longo da Estrada do Viamão, as ações da nova estrutura administrativa encaminharam-se no sentido de reconhecimento do território e seu "povoamento". Ao longo do período coberto pelas fontes consultadas (1853-1947), percebemos que as medidas tomadas pelos governantes traduzem um esforço contínuo de "domínio" do território, implicando em diversas formas de relações com a natureza, conforme afirma Milton Santos,

a história das chamadas relações entre sociedade e natureza é, em todos os lugares habitados, a da substituição de um meio natural, dado a uma determinada

1 Essas fontes estão disponíveis na rede mundial de computadores nos sítios do Arquivo Público do Estado do Paraná http://www.pr.gov.br/arquivopublico/relatorio_pres.shtml, http://www.pr.gov.br/arquivopublico/mensagens_gov. shtml e no sitio do Projeto de Imagens de Publicaçõos Oficiais brasileiras do Center for Research Libraries e Latin American Projects http://www.crl.edu/content/provopen.htm 
sociedade, por um meio cada vez mais artificializado, isto é, sucessivamente instrumentalizado por essa mesma sociedade. Em cada fração da superfície da terra, o caminho que vai de uma situação a outra se dá de maneira particular; e a parte do "natural" e do "artifical" também varia, assim como mudam as modalidades do seu arranjo. ${ }^{2}$

No caso particular, o dos rios, as Mensagens evidenciam as várias maneiras de sua "instrumentalização", que vai desde seu uso como "divisas e fronteiras naturais", estradas, orientação geográfica de projetos ferroviários até, na sua maior alteração ambiental, ou artificialização, a construção de barragens para a geração de energia elétrica. Cada um desses momentos é marcado pelo que Milton Santos denomina de "objetos técnicos": um mapa projetando uma hidrovia, um porto com balsa, uma ponte, ou uma hidroelétrica. ${ }^{3}$

Alguns dos objetos técnicos mencionados por Santos, como as hidroelétricas e as cidades impactam tão fortemente o meio que se metamorfoseiam em "paisagem natural". Em outros casos, como os dos pequenos portos, das pontes, ou mesmo os dos mapas depositados nos arquivos, as motivações, apropriações e representações inerentes àqueles objetos parecem desaparecer. Afinal, enxergamos a ponte, mas raramente percebemos os rios que passam por baixo. Nesse sentido, esse artigo busca examinar, especialmente, duas formas de relacionamento da sociedade com os rios no Estado do Paraná, através das ações das autoridades governantes: a necessidade de construção de pontes e o surgimento da era das "barragens".

\section{A história ambiental e os objetos técnicos}

Regina Horta Duarte, ${ }^{4}$ analisando o surgimento e crescimento do campo da história ambiental em obras publicadas no Brasil, especialmente na década de 1990 e início do século XXI, fez algumas considerações de suma importância para ao historiador ambiental. Duarte aponta para a necessidade de analisarmos três questões para o desenvolvimento, ou construção, de uma História Ambiental:

O determinismo aparece como uma primeira questão epistemológica, seguido da tradicional tendência histórica à busca de origens. Finalmente, os pressupostos ontológicos da história apresentam-se como terceiro item a ser debatido. ${ }^{5}$

2 SANTOS, Milton. A natureza do espaço: técnica e tempo, razão e emoção. 2.ed. São Paulo: Hucitec, 1997, p.186.

3 SANTOS, Milton. A natureza do espaço, p.201.

4 DUARTE, Regina Horta. Por um pensamento ambiental histórico: o caso do Brasil. Luzo-Brazilian Review, University of Wisconsin Publisher, v.41, n.2, p.144-161, 2005.

5 DUARTE, Regina Horta. Por um pensamento ambiental histórico, p.148-149. 
O nosso objetivo é o de analisar as relações do "governo" do Estado do Paraná com os rios do território paranaense. A leitura das Mensagens dos presidentes da Província e dos presidentes do Estado no período 1854-1947, permite indicar algumas das principais características dessa relação. É possível, então, estabelecer uma periodização do objeto em análise a partir do significado, ou importância, que uma forma específica de apropriação assumiu em determinado período: do surgimento da Província em 1853 até a década de 1870, os rios foram imaginados e tratados, principalmente, como possíveis estradas; desse perío do até os anos 1920, eram referências espaciais e lugares que interrompiam o trajeto das estradas nos quais deveriam ser construídas pontes. A partir desse momento, mas mais explicitamente na década de 1940 e início da de 1950, os rios começaram a aparecer com a sua função mais recente, o de fornecedor potencial de energia elétrica.

Essas são as mudanças significativas existentes nas formas como as autoridades da Província/Estado imaginaram, ou se apropriaram, dos rios do Paraná. Nesse sentido, o estabelecimento de um porto, a fixação de uma balsa, a construção de uma ponte, o planejamento de uma barragem representam diversas temporalidades de intervenção técnica no natural. Olhar esse espaço, atualmente, significa deparar-se com essas diversas temporalidades da paisagem fixadas nos objetos técnicos construídos pelo homem ao longo dos cursos dos rios. A tarefa da história ambiental seria, então, buscar as permanências e mudanças significativas ocorridas nas intervenções promovidas pelo Estado nos rios, como uma estratégia para compreender o "significado da natureza na história humana". Porém, corremos o risco de, como alertou Regina $\mathrm{H}$. Duarte, na busca de um rio idealizado, natural, existente em um passado mítico, estabelecer uma hierarquia sucessória dos objetos técnicos, testemunhos daquela relação, do mais simples e antigo ao mais complexo e moderno: dos passadores de balsa até a barragem das usinas hidroelétricas. Assim, as hidroelétricas seriam o último passo da marcha triunfante da destruição ambiental inerente à sociedade brasileira. Essa perspectiva é criticada pela autora. Mencionamos a usina hidroelétrica de forma proposital, pois esse objeto técnico aparece atualmente como a maior ameaça à "preservação" da integridade do rio natural. ${ }^{6}$ Mas são as barragens que têm mobilizado e influenciado o posicionamento contemporâneo, e isto ilumina o "lugar social" do historiador ambiental. Nossa percepção dos rios é, portanto, uma somatória de apropriações e representações, funções, conforme Lucien

6 Para o rio Tibagi, um dos últimos grandes rios do Estado do Paraná, livre de barragens, existe um plano de aproveitamento feito pelas autoridades federais e estaduais que prevê a construção de sete barragens. Essa previsão data da década de 1960. Em fins de 2006, a ANEEL licitou a construção da Usina de Mauá, no salto de mesmo nome no rio Tibagi, provocando intensa polêmica e reação de ambientalistas, cientistas e povos indígenas. Ver o site da ONG Liga Ambiental: http://www.ligaambiental.org.br 
Febvre, sobrepostas. ${ }^{7}$ Algumas dessas formas desapareceram quase sem deixar marcas na natureza, outras continuam presentes compondo a paisagem dos rios do território paranaense, testemunhando a história das relações entre homens e rios. ${ }^{8}$

\section{Estradas e pontes: os rios "ocultos"}

$\mathrm{Na}$ primeira mensagem enviada à Assembléia Legislativa, o primeiro presidente da província do Paraná, Zacarias Góes e Vasconcellos, ${ }^{9}$ aparecem claramente; as demandas pela montagem da estrutura administrativa para a nova província; a necessidade de se conhecer os limites e o interior do território que era, como em quase todas as províncias do país, praticamente desconhecido pelas autoridades. Entre as referências geográficas, os cursos d'água estão entre os de maior facilidade de uso pelos governantes na determinação das localidades e divisas com as outras províncias. Mas não só, como estava no horizonte da administração a construção de um território reconhecido e povoado por outros grupos étnicos, os rios comparecem também como possibilidades de "estradas", situação na qual os rios tornavam-se obstáculos nos caminhos.

As primeiras ações governamentais, ou estabelecimento do que podemos chamar de "políticas de governo", sobre os rios foram de conhecer a utilidade destes para a navegação, o seu uso como estradas para facilitar a comunicação e o comércio. Após as "entradas" promovidas pelo Barão de Antonina na década de 1840, continuou-se a buscar uma rota para 0 Mato Grosso depois da criação da província. Durante a Guerra do Paraguai, investiu-se em muitas expedições ao longo dos rios Tibagi, Paranapanema e Ivai para determinar qual seria o melhor traçado da rota fluvial com destino ao oeste. Do ponto de vista do Império era uma forma de escapar da navegação do rio Prata, até então a via de acesso mais rápida a Província do Mato Grosso. Para os "paranaenses" abriria a possibilidade de uma rota comercial entre o Paraná e aquela Província. Entretanto, deixaremos essa

7 FEBVRE, Lucien. O Reno, mitos e realidades. Rio de J aneiro: Civilização Brasileira, 2000.

8 Regina Horta Duarte alerta para o risco de idealização da natureza: "Apresentar a idéia de natureza como um conceito historicamente construído não implica em concluir que a natureza seja apenas uma idéia. Não se trata de substituir uma perspectiva objetivista por outra subjetivista, mas sim de pensar nas relações humanas em que se constituem formas de pensar e agir sobre o mundo natural". In: DUARTE, R. H. Por um pensamento ambiental histórico, p.154. Nesse sentido, as pontes, os portos, as usinas, os objetos técnicos mencionados por Milton Santos, são os documentos de que a natureza não é uma idealização. Em outro sentido Dora S. Corrêa fez uma crítica contundente a uma determinada perspectiva da história ambiental que procura, ou pretende, mudar os protagonistas da história, isolando a natureza do mundo humano, "como se ela fosse exterior a ele". (p.47) Para Corrêa: "Essa abstração apresenta-se necessária a fim de se atingir um dos objetivos dessa especialidade: mudar os protagonistas tradicionais dessa ciência humana, substituindo-os pela matas, pelas saúvas, pelos vírus, num processo de personificação da natureza". CORRÊA, Dora Shellard. Paisagens Sobrepostas. Índios, posseiros e fazendeiros nas Matas de Itapeva. (1723-1930). São Paulo: USP, 1997, p.47. (História, Tese de Doutorado).

9 VASCONCELLOS, Zacarias de Góes e. Relatório do Presidente da Província do Paraná, o Conselheiro(...), na abertura da Assemblea Legislativa Provincial em 15 de julho de 1854. Curityba: Typ. Paranaense de Candido Martins Lopes, 1854. 
temática para outra oportunidade. 0 objetivo central nesse artigo, como foi dito acima, são as outras formas da relação governo e rios, como a percepção de que as passagens (vaus) eram estratégicas na arrecadação de impostos.

A constituição da estrutura legal e burocrática de uma nova província lançava também suas teias de controle sobre as águas, ou melhor, sobre as atividades que se exercem ou podem ser exercidas nesses rios. Já em 1855 , na segunda mensagem que o presidente Góes e Vasconcellos remetia a Assembléia Provincial, aparecia a denúncia de que particulares estavam cobrando por passagens em rios e pontes:

No rio Guaraúna, J osé Pereira Bueno, no Embetuva, Francisco das Chagas; no da Ponte-Alta, J osé Antonio de Miranda; e outros, nas estrada de Palmeira a Palmas por Guarapuava, cobrão taxas dos passageiros, uns por pontes, que tem construído, e outros por balsas e canoas que conservão nos passos dos rios: assim o informa de vista o empregado da thesouraria, que foi estabelecer a agência no Xapecó. Ora, não é isso deixar aos particulares, contra todas as regras de administração e de polícia, uma renda, que tanta falta faz aos mirrados cofres municipaes? Cumpre pôr termo a tal abuso. ${ }^{10}$

O Estado, sua máquina burocrática e arrecadatória em início de funcionamento, percebia na passagem dos rios, os vaus, uma bom local para estabelecer a cobrança de impostos. Na passagem do Rio Negro, no sul da Província, por onde ocorria a entrada das rezes e muares oriundos do Rio Grande do Sul, com destino à feira de Sorocaba, em São Paulo, foi instalada uma barreira para cobrança. A regulamentação do Registro de Rio Negro, no seu artigo 28, dizia: "Fica prohibida a existência de canoas particulares no Rio-Negro em distancia de quatro léguas, quer para baixo, quer para cima do lugar em que se acha a balsa". ${ }^{11} \mathrm{O}$ aparato estatal tentava impedir a passagem de animais sem a devida cobrança de impostos. 0 rio era, para os administradores, apropriado como um obstáculo que, bem administrado, sujeitaria todos à cobrança dos impostos estabelecidos. Mais à frente, no mesmo regulamento, no artigo 37, regulamenta-se a função de "passadores de balça [sic] e canoas do Rio-Negro" como funcionários do Estado, nomeados pelo governo. Determinadas características naturais dos rios, como corredeiras, largura do leito e margens acidentadas direcionavam os caminhos para as passagens mais tranqüilas e, assim, acabava por "determinar" as estratégias das autoridades.

10 VASCONCELLOS, Zacarias de Góes e. Relatório do Presidente da Província do Paraná. O Conselheiro Zacarias de Góes e Vasconcellos na abertura da Assembléia Legislativa Provincial em 8 de Fevereiro de 1855. Curityba: Typographia Paranaense C.M.Lopes, 1855, p.79.

11 VASCONCELLOS, Zacarias de Góes e. Relatório do Presidente da Província do Paraná. O Conselheiro Zacarias de Góes e Vasconcelos na abertura da Assembléia Legislativa Provincial em 8 de Fevereiro de 1855, p.163. 
Os rios apareciam nas primeiras décadas da província como uma grande possibilidade para facilitar a penetração ao interior do território e estabelecer rotas de comunicação com a vizinha província do Mato Grosso. No entanto, em decorrência do sentido do principal caminho já estabelecido na região, a estrada do Viamão, que cortava o Paraná no sentido sul/nordeste, atravessando o território paranaense diagonalmente, a passagem dos inúmeros rios tornava-se uma preocupação constante das autoridades provinciais. A necessidade de estabelecer os vaus possíveis e construir pontes é uma constante nas mensagens e relatórios do governo. Embora a preocupação com as pontes seja uma constante na documentação, a perspectiva de maior significado em relação aos rios, até a década de 1870 era, sem dúvida, a possibilidade de transformá-los em "caminhos que andam".

As pontes, porém, são objetos técnicos que permitem aos homens superarem ou transformarem os limites impostos pelo meio natural, 'tecnologias' criadas para a apropriação do natural. ${ }^{12}$ Nesse caso, a circulação de homens, animais e mercadorias por caminhos de terra. É nesse sentido que se deve entender a preocupação constante das autoridades com as pontes e as estradas.

Em 1856, o presidente, engenheiro Henrique Beaurepaire Rohan, informando sobre as estradas existentes na província nos permite avaliar a importância da chamada "Estrada Geral das Tropas":

Esta estrada, por meio do qual se communica a província de São Paulo com a do Rio-Grande do Sul, em de extensão 67 léguas, na parte que pertence ao Paraná, desde o Itararé, limite norte, até o Canoinhas, limite sul da província. Atravessa sucessivamente de N. a S., a parochia de J aguariahyva, as villas de Castro e Ponta-Grossa, a parochia da Palmeira, a villa do Príncipe e a parochia do Rio-Negro, até entrar na província de Santa Catharina, pelo município de Lages. É por ella e suas ramificações que se faz o importante commercio das tropas, de que tão avultado interesse resulta aos cofres da província. ${ }^{13}$

A manutenção das estradas por onde passavam as tropas, cuja cobrança das taxas de passagem representava uma parte importante da arrecadação dos tributos da província, motivava a preocupação constante com as pontes e com os varadouros que perduraria por largo tempo nas falas das autoridades.

12 Para uma discussão conceitual sobre "tecnologia e apropriação da natureza" no campo da "ciência sócioambiental" ver DRUMOND, J osé Carlos. Ciência socioambiental: notas sobre uma abordagem necessariamente eclética. In: ROLIM, Rivail Carvalho, PELLEGRINI, Sandra Araújo e DIAS, Reginaldo. (eds.) História, espaço e meio ambiente. Maringá: Anpuh/PR, 2000, p.21-23.

13 ROHAN, Henrique de Beaurepaire. Relatório apresentado a Assembléa Legislativa Provincial do Paraná no dia 01 de março de 1856 pelo vice-presidente em exercício Henrique de Beaureaire Rohan. Curityba: Typ. Paranaense de C. Martins Lopes, 1856, p.108. 
Em 1860, o presidente da província, J osé Francisco Cardoso, em seu relatório de passagem de governo com 68 páginas, dedicou cerca de 05 para tratar das pontes e pontilhões que seria necessário construir. No rio Barigui (Bariguy), havia sido contratado o major Vicente Ferreira da Luz para construir uma ponte com 70 palmos de comprimento e 20 de largura; no rio do Tobias, o mesmo contratado deveria construir uma com 30 palmos de comprimento e 20 de largura. No mesmo Barigui, na estrada da Ordem, foi construída e doada uma ponte pelo cidadão J oão de Sant'Anna, que tinha “(...) 44 palmos de comprimento e toda a construção é de sólidas madeiras de lei". Ainda nesse rio, na estrada do Iguaçu, foi incumbido Antonio J osé de Oliveira Leme para construir uma ponte por 600 mil réis. No Iguaçu, foi investido 400 mil réis para fazer os reparos necessários pelo tenente Luiz Antonio de Sá Ribas. No rio Capivari Mirin (Capivarimerim) foi gasto mais 300 mil réis; no Itaqui, a ponte estava sendo construída por Manoel de Bastos Coimbra; no "Ivahysinho", estavam sendo construídos açudes e reparadas as cabeceiras da ponte. Já no rio Pequeno, a ponte foi orçada em 350 mil réis e foi contratado o cidadão Basos Coimbra para construir uma ponte com 30 palmos de comprimento e 20 de largura. Foi mandado construir pontilhões na estrada de Barreiros. A de Ponte Alta ficaria em um conto de réis, mas a sua construção era "indispensável". No Taboazinho, gastou-se 500 mil réis para construir uma ponte e seria necessário 800 mil réis para fazer uma em Reserva, um conto de réis no Cavosinho. Foram feitos reparos nas pontes de Canoinhas, do rio São J oão, do Butiá, do São Lourenço e, no rio da Vargem, gastou-se 80 mil réis para os reparos iniciais. No Palmital foram reparadas duas pontes. ${ }^{14}$

O sucessor de José Francisco Cardoso, Antonio Barbosa Gomes Nogueira, no seu relatório de 1862, descreve de forma mais completa e detalhada o estado das estradas da província, no qual aparecem, também, as pontes e os rios. Na sua exposição, além das pontes que já haviam sido construídas, mandadas construir ou reformar, menciona as que precisariam ser urgentemente edificadas. Na estrada da Palmeira ao Porto União, importante rota do comércio de muares, havia a necessidade de construção de uma ponte sobre o rio Claro, com mais de 200 palmos de cumprimento (cerca de 60 metros). Como seria uma despesa muito grande para os cofres da recém-criada província, a solução foi mandar “(...) postar 2 canoas que o encarregado da estrada já me communicou ter contractado por $120 \$ 000$ para estarem promptas brevemente; assim como que ajustara por $30 \$ 000$, dous concertos em dous aterros além do rio". ${ }^{15}$ Também no rio J angada, na

14 CARDOSO, J osé Francisco. Relatório que o Exm. Sr. J osé Francisco Cardoso Apresentou ao Exm. Sr. Dr. Antonio Barbosa Gomes Nogueira ao passar-lhe a Administração do Paraná. Coritiba: Typografia do Correio Oficial,1861, p.56-61.

15 NOGUEIRA, Antonio Barbosa Gomes. Relatório apresentado a Assemblea Legislativa da Província do Paraná na Abertura da primeira sessão da Quinta Legislatura, 15/02/18, p.68-69. 
estrada de Palmas a Porto União, foi autorizado a "(...) contractar um indivíduo para dar passagem no rio J angada e bem assim a mandar construir duas canoas para semelhante serviço". ${ }^{16} \mathrm{Na}$ estrada de Castro ao Itararé, além de diversas obras muito detalhadas que aparecem no relatório, 0 presidente ordenou que

(...) afim de terem livre transito as tropas, que, no passo do rio lapó ao Guartelá, fosse feito um boeiro de madeira de lei e os esgotos necessários: e pretendo ahi collocar um passador com canoa para poupar os tropeiros este dispêndio. ${ }^{17}$

A necessidade de facilitar a passagem em rios nos quais seria muito difícil a construção de pontes, devido os custos da edificação, obrigava a contratação de "passadores" através de canoas e balsas. Os rios, vistos como obstáculos, criavam uma profissão, ou uma atividade remunerada pelo Estado.

Havia também, para o presidente, as pontes de "urgente necessidade" que eram: uma no rio Tibagi, na estrada da Palmeira a Ponta Grossa; uma no rio lapó, na cidade de Castro; uma no rio J aguaricatu e uma no rio J aguariahyva. A do rio Tibagi estava sendo construída por 7:000\$000 contos de réis, projetada pelo engenheiro Chandler e executada pelo "inteligente carpinteiro Eleutério de Almeida Pontes". 0 rio lapó, em Castro, tinha uma ponte mas que necessitava urgente de reparos provisórios, para que as tropas "(...) pudessem por ella passar para a feira de Sorocaba nos mezes de abril e maio". ${ }^{18}$

Construir estradas e mantê-las parece ter sido uma obsessão dos governantes do Paraná desde a sua criação em 1854. A explicação pode ser encontrada nas relações entre autoridade e formação do território. Estradas significavam a presença do poder, a transformação da natureza em território administrado. Em uma fala de 1894, do presidente Francisco Xavier da Silva, essa motivação aparece claramente: "Uma das necessidades à que cumpre sempre attender-se é cortar de estradas o vasto e riquíssimo território do Estado, e melhorar as existentes" ${ }^{19}$ O cupar o espaço significava aumentar a apropriação da natureza no sentido da moderna sociedade capitalista e, também, ampliar as ações de re-ocupação do território, até então controlado, ou pelo menos com presença marcante, em grande parte por sociedades indígenas, especialmente as áreas a oeste do rio Cinzas,

16 NOGUEIRA, Antonio Barbosa Gomes. Relatório apresentado a Assemblea Legislativa da Província do Paraná na Abertura da primeira sessão da Quinta Legislatura, 15/02/1862, p.69.

17 NOGUEIRA, Antonio Barbosa Gomes. Relatório apresentado a Assemblea Legislativa da Província do Paraná na Abertura da primeira sessão da Quinta Legislatura, 15/02/1862, p.71.

18 NOGUEIRA, Antonio Barbosa Gomes. Relatório apresentado a Assemblea Legislativa da Província do Paraná na Abertura da primeira sessão da Quinta Legislatura, 15/02/1862, p.73-74.

19 SILVA, Francisco Xavier da. Mensagem do govemador do Estado, enviada e lida perante o Congresso Legislativo do Paraná em 20/10/1894. Curitiba: Typ e Lith. Cia Impressora Paranaense, 1984, p.09. 
norte do rio Iguaçu e o rio Paraná. ${ }^{20}$ Tais ações eram características do estado-nação-moderno. ${ }^{21}$ É preciso esclarecer que a presença dos objetos técnicos, pontes e estradas, limitava-se, até o início do século XX, a uma estreita faixa a leste do rio Tibagi, e ao sul, divisa com Santa Catarina. No centro, os limites eram a região de Guarapuava.

Os rios como meio de transporte foram, nas propostas e ações governamentais, gradualmente sendo substituídos por estradas de rodagem e, depois, por ferrovias. Mas as estradas precisavam "vencer o rio" através de vaus, pontilhões, aterros e pontes que estavam sendo construídas. Em 1915, o presidente do Estado informava que haviam sido reformadas ou construídas 1038 metros lineares de pontes durante 0 ano anterior. ${ }^{22}$ No ano seguinte, o presidente foi mais específico e informou que durante o seu período frente à administração do Estado haviam sido construídos um total de 2.400 metros lineares de pontes, pontilhões e boeiros..$^{23}$

Pode se concluir que a preocupação em mencionar nas Mensagens a quantidade de metros de pontes, pontilhões e boeiros construídos ou reformados indica a presença constante dos rios nas ações das autoridades. Ao projetar a presença do Estado no território, através de sua re-ocupação, os governantes se depararam com a realidade do natural, rios como o Tibagi, - Ivai, o lapó, ou o Iguaçú, eram obstáculos que precisavam ser "vencidos" para se constituir a apropriação da natureza através da abertura de estradas. Além disso, projetando hipoteticamente uma média de 40/50 metros de largura entre margens para cada rio, teríamos a intervenção humana em pelo menos 40/50 rios, somente no ano de 1916. A ação humana, gradualmente, "reorganizava" a natureza através da implantação de "objetos técnicos", muitos dos quais desapareceriam sem deixar maiores mudanças no natural, já outros permaneceriam como documentos da intervenção humana. ${ }^{24}$

Por fim, finalizando a análise da "presença oculta" dos rios nas Mensagens, mencionaremos a primeira ponte construída sobre o rio Paranapanema. É significativo que a construção dessa ponte sobre o rio Paranapanema, na região nordeste do Estado, ligando os municípios de Ourinhos-SP e J acarezinho-PR, tenha se tornado digna de menção em Mensagens do pre-

20 A idéia de re-ocupação foi desenvolvida por Nelson Dácio Tomazi, para explicar as formas de legitimação do processo de colonização recente da região norte do Estado do Paraná, que negavam ou ocultavam os ocupantes anteriores. TOMAZI, Nelson Dácio. Norte do Paraná: história e fantasmagorias. Curitiba: UFPR, 1997. (História, tese de Doutorado).

21 Esse momento representa o surgimento do estado-nação moderno com suas ações de constrição do território nacional bem como o surgimento das disputas imperialistas. Ver SEVCENKO, Nicolau. Literatura como missão. São Paulo: Brasiliense, 1983 e HOBSBAWM, Eric J. A era dos Impérios. Rio de J aneiro: Paz e Terra, 1988. Sobre os territórios indígenas e a "guerra de conquista" ver: MOTA, Lúcio Tadeu. 0 aço, a cruz e a terra: índios e brancos no Paraná provincial (1853-1889). Assis-SP: UNESP 1998. (História, tese de Doutorado).

22 ALbuQuerque, Carlos Cavalcanti de. Mensagem dirigida ao Congresso Legislativo do Estado do Paraná ao installar-se a 2a Sessão da 12a Legislatura em 01/02/1915. Curitiba: Typ. d'A República, 1915, p.30.

23 ALBUQUERQUE, Carlos Cavalcanti de. Mensagem dirigida ao Congresso Legislativo do Estado ao installar-se a 1 à Sessão da 13a Legislatura. Curitiba: Typ. do Diário Oficial, 1916, p.39.

24 Sobre a "reorganização do natural" ver WORSTER, Donald. Transformações da terra: para uma perspectiva agroecológica na história. Ambiente\& sociedade, Campinas, vol.5 n.2 vol.6 n.1, p.23-44, 2003. 
sidente do Estado do Paraná e do Estado de São Paulo. A sua inauguração contou com a participação dos dois presidentes. A ponte foi construída em madeira e ferro com 184 metros de comprimento. ${ }^{25} \mathrm{~A}$ região, posteriormente denominada de "norte velho", tornara-se, desde o final do século XIX, a primeira e principal produtora de café do Estado do Paraná:

Em 08 de novembro findo foi inaugurada a ponte sobre o rio Paranapanema, ligando este Estado ao de S.Paulo, com a presença dos Presidentes dos dois Estados (...). Para a execução desse importante melhoramento, que actualmente vem beneficiar consideravelmente a nossa lavoura de café, facilitando o transporte do seu producto, este Estado concorreu com o auxílio de 50:000\$000. ${ }^{26}$

No início dos anos de 1920 foi construída uma outra ponte, alguns quilômetros a montante no rio Paranapanema, ligando os municípios de Ribeirão Claro-PR e Chavantes-SP, no Porto Emygdão:

\begin{abstract}
Attendendo ao auxílio pedido por vários moradores dos municípios de J acarezinho e Ribeirão Claro, o Governo autorizou a construcção de um ponte pencil de $77 \mathrm{~m} 10$ de vão livre sobre o Rio Paranapanema no Porto Emygdão, na estrada de Ribeirão Claro e Chavantes. Para execução desse melhoramento cujos serviços estão em andamento, o Paraná concorrerá com 50:000\$000, concorrendo o resto das despesas por conta dos demais interessados. ${ }^{27}$
\end{abstract}

Mas nem sempre a tecnologia empregada era suficiente para "vencer" a natureza. As vezes, fenômenos naturais, como enchentes, destruía os objetos técnicos resultantes da pretensão humana de dominá-la. Nesse caso, a ponte foi destruída, "(...) no início do ano de 1922 pelas 'enchentes excepcionais verificadas em princípio do ano passado (...)", conforme informava o presidente do Estado em 1923 ao prestar auxílio de 15:000\$000 aos fazendeiros da região para reconstruí-la. ${ }^{28}$

Atualmente a ponte tornou-se patrimônio histórico do Paraná, tendo sido restaurada no final dos anos 1980 , encontrando-se novamente deteriorada. De uma iniciativa de incorporação do território, representando uma idéia de progresso, vencendo os obstáculos nos quais os rios haviam se transformado, hoje é um monumento de memória e identidade, um patrimônio. Mas o rio, o rio continuou correndo por baixo da ponte, como corria antes de sua construção.

25 ARANTES, Altino. Mensagem apresentada do Congresso Legislativo do Estado de São Paulo em 14/07/1917. São Paulo: s. ed., 1917, p.65.

26 CAMARGO, Affonso Alves. Mensagem dirigida ao Congresso Legislativo do Estado pelo presidente ao instalar a 1a Sessão da 14a Legislatura em 01/02/1918. Curitiba: Typ. D'A Republica, 1918, p.17.

27 CAMARGO, Affonso Alves. Mensagem dirigida do Congresso Legislativo do Estado do Paraná na 1a Sessão da 15a Legislatura em 01/02/1920. Curitiba: Typ. d'A República, 1920, p.59.

28 ROCHA, Caetano Munhoz da. Mensagem ao Congresso Legislativo do Paraná ao installar-se a 2a Sessão da 16a Legislatura em 01/02/1923. Curitiba: s.ed, 1923, p.69. 


\section{Navegação e imaginário geográfico}

Embora, como foi dito acima, a análise estaria restrita a dois aspectos principais, os rios como obstáculos a circulação, aparecendo com "presença oculta" nos documentos e, em segundo lugar, como "força hydráulica", é importante abordar rapidamente duas outras perspectivas de apropriação dos rios, a de referencia geográfica para os projetos de construção de ferrovias e a de navegação. Alguns rios, como o Tibagi e o Paranapanema, já haviam perdido, desde o final da década de 1870, sua importância nos projetos de navegação nos discursos governamentais. Entretanto, outros continuavam a ser navegados por embarcações a vapor, como Iguaçu, 0 Negro e o Paraná. Mesmo o rio Ivai, que durante a Guerra do Paraguai havia sido explorado para examinar sua navegabilidade por barcos a vapor, ainda mobilizava o Estado e alguns interessados, na segunda década do século XX. Em 1920 ao relatar a situação da navegação no Estado, o presidente Affonso Alves Camargo informava que

(...) abrangia os rios Paraná, Iguassú, [sic] Negro e Potinga, sendo que a do rio Paraná continua a ser feita por firmas argentinas (...). A navegação dos demais rios mencionados é feita pelo Lloyd Paranaense. Usando a autorização contida na lei 1702, de 29/03/1917, o Governo contractou com o sr Wenceslau Glaser os serviços de melhoramentos de navegação do rio Ivahy, sendo que o pagamento dos trabalhos será effetuado em terras devolutas. ${ }^{29}$

Embora nas Mensagens a rota fluvial com destino ao Mato Grosso tenha ocupado uma importante parcela das discussões e ações das autoridades até o último quartel do século XIX, a navegação de outros rios era praticada e mesmo incentivada. Mas não assumia importância fundamental nos projetos de apropriação do território, como na rota para o Mato Grosso.

Quando as ferrovias passaram a freqüentar o primeiro lugar nos projetos e desejos das autoridades do Estado para re-ocupação do território, no último quartel do século XIX, os rios começaram a aparecer nos documentos governamentais com outro significado. Além de caminhos tornaram-se, também, referências geográficas para os projetos das ferrovias. De certa maneira, os cursos dos rios acabavam por determinar os projetos dos pedidos de concessões de estrada de ferro. Em 1906, foi deferida "[...]a Augusto Hauer a concessão de uma estrada de ferro entre Ponta Grossa ou suas proximidades e a margem do Paranapanema, entre os valles do Tibagy e o Ivahy, mediante vários favores mas sem garantia de juros". ${ }^{30}$

29 CAMARGO, Affonso Alves. Mensagem dirigida do Congresso Legislativo do Estado do Paraná na 1a Sessão da 15a Legislatura em 01/02/1920, p.63.

30 LIMA, Vicente Machado da Silva. Mensagem ao Congresso Legislativo do Estado do Paraná enviada pelo presidente do Estado ao installar-se a 2a Sessão da 8a Legislatura em 01/02/1907. Curitiba: Annibal Rocha \& Cia, 1907, p.21. 
Em 1919, o presidente, após enumerar uma série de estradas e ferrovias existentes e recém-terminadas no Estado, considerava que o sistema de viação só ficaria completo "(...) com as futuras estradas de ferro, que forçosamente terão de correr pelos ubérrimos valles do Iguassu, Piquiri, Ivahy, Tibagy e Paranapanema, para a ligação do Atlântico com o magestoso Paraná". ${ }^{31} \mathrm{Em} 1923$ foi assinado um contrato com a Companhia Marcondes de Colonização, Indústria e Commércio para a construção de uma ferrovia, de bitola de um metro, a vapor ou eletricidade, cujo traçado partiria da região do município de Irati para que

(...) atravesse os municípios de Imbituva e Prudentópolis e siga pelo valle do Ivahy, até a sua foz e com três ramaes, dos quaes um partirá de um ponto conveniente da linha principal e seguirá pelo valle do rio Pirapó, até a margem do rio Paranapanema. ${ }^{32}$

Pode-se considerar que a utilização dos rios como delimitação espacial nos projetos ferroviários mencionados decorre do fato que todos eles eram destinados a regiões que, no período, ainda estavam fracamente exploradas por terra devido as extensas florestas e a presença significativa de grupos indígenas. Entretanto, os rios já haviam sido navegados, explorados e mapeados desde a primeira metade do século XIX permitindo aos governantes uma projeção imaginária do território a partir dos referenciais dos rios mencionados. Fenômeno semelhante ocorreu no oeste do Estado de São Paulo no início do século XX, considerado como "região pouco explorada" foi incorporada simbolicamente ao território paulista após as expedições realizadas pela Comissão Geográfica e Geológica, em 1905, nos rios Feio, Peixe, Tiete e Paraná.

\section{A era da "força hydráulica": os rios "visíveis"}

De todas as formas de apropriações, simbólicas ou concretas, as quais os rios foram submetidos, nenhuma delas provocou tanta alteração na suas configurações naturais quanto o aproveitamento da força hidráulica para produção de energia elétrica. A expansão dessa tecnologia, a partir do início do século XX, mudaria a percepção e os aspectos valorizados dos rios presentes nos discursos governamentais existentes nas Mensagens. Embora, a primeira hidroelétrica, a Usina de Chaminé, nos arredores de Curitiba tenha sido inaugurada apenas no início dos anos de 1930, a implementação concreta da era das grandes barragens começaria somente a

31 CAMARGO, Affonso Alves. Mensagem dirigida ao Congresso Legislativo do Estado do Paraná na 2ª Sessão da 14ª Legislatura em 01/02/1919. Curitiba: Typ. d'A República, 1919, p.29.

32 ROCHA, Caetano Munhoz da. Mensagem ao Congresso Legislativo do Paraná ao installar-se a 2a Sessão da 16a Legislatura em 01/02/1923, p.75. 
partir dos anos 1960. Para entender a mudança significativa da percepção de quais características naturais dos rios passaram a ser valorizadas é necessário analisar o surgimento e expansão do uso dessa nova tecnologia, a eletricidade. Novas tecnologias impõem novas demandas ao natural, portanto, se anteriormente as corredeiras e quedas foram percebidas como "obstáculos" para o desejo de apropriar-se dos cursos d'água como estradas, agora os "acidentes altimétricos" passavam a ser vistos como "riqueza" natural a ser explorada.

Nesse artigo, apenas se apresentará os momentos iniciais, de planejamento do que se pode chamar da "era das barragens", através do surgimento e expansão da demanda por energia elétrica no Estado, especialmente em sua capital, Curitiba. No início, na primeira década do século XX, operada por concessões, era uma atividade essencialmente privada, se transformou em uma atividade essencialmente estatal, no decorrer da década de 1950, cujo marco foi a criação da Companhia de Energia Elétrica do Estado do Paraná - COPEL, em 1954.

O aproveitamento da energia hidráulica para produção de eletricidade não era desconhecido, obviamente, pelas autoridades paranaenses. Em 1913, uma notícia de que o governo do Estado do Mato Grosso pretendia abrir uma concessão para o aproveitamento da "força hydráulica" das Sete Quedas no rio Paraná mobilizou rapidamente o presidente do Estado que, através de telegramas, fez ver ao presidente do Estado vizinho o direito de posse do Paraná naquelas quedas. ${ }^{33}$

0 aproveitamento da energia hidráulica no Estado surge, nos documentos, associado ao fornecimento de energia elétrica para iluminação pública para a capital do Estado. No início dos anos de 1910 esse serviço estava a cargo da The South Brazilian Railways Limited, que operava através de usinas térmicas, o que não agradava nem atendia às necessidades da demanda, conforme expressava o presidente do Estado naquele momento. 0 referido serviço precisava ser, talvez, triplicado na quantidade: "Apesar do grande aumento que tem tido o número de focos empregados, ainda assim esse número não é proporcional a área cada vez mais extensa da cidade que exigiria talvez a triplicação na intensidade da luz existente". ${ }^{34}$ Havia um contrato de concessão para o aproveitamento da "(...) força hydráulica das cachoeiras do Caiacanga, no rio Iguassu, parecendo, entretanto, que a empreza concessionária, não pretende realizar tal emprehendimento(...)" ${ }^{35}$

33 ALbuquerque, Carlos Cavalcanti de. Mensagem dirigida ao Congresso Legislativo do Estado do Paraná ao installar-se a 2a Sessão da 11a Legislatura em 01/02/1913. Curitiba: Typ do Diário Official, 1913, p.08.

34 ALBUQUeRQue, Carlos Cavalcanti de. Mensagem dirigida ao Congresso Legislativo do Estado do Paraná ao installar-se a 2a Sessão da 11a Legislatura em 01/02/1913, p.23.

35 ALBUQUERQUE, Carlos Cavalcanti de. Mensagem dirigida ao Congresso Legislativo do Estado do Paraná ao installar-se a 2a Sessão da 11a Legislatura em 01/02/1913, p.23. 
Em 1918 o presidente Affonso Alves Camargo informava que o fornecimento de eletricidade para a capital continuava sob a responsabilidade da mesma firma e que "as demais cidades do Estado são illuminadas por conta das respectivas municipalidades, sendo que em quase todas ellas a energia electrica é o systema empregado". ${ }^{36}$

Em 1926, o problema de atendimento continuava e o presidente ao comentar o uso de "usina térmica" para o fornecimento de energia elétrica, afirmava:

Comprehende-se que não poderá persistir esse systema incompatível com 0 crescente progresso de Curytiba (...) tornando-se urgente que se leve a efeito a installação hydro eléctrica. (...). Não se pode contar muito com as empresas particulares (...). Infelizmente não logrou êxito a Prefeitura do Município de Curitiba (...) de promover os meios de acquisição dos serviços de luz e de força (...). ${ }^{37}$

Aparece, assim, claramente no discurso dos governantes estaduais a necessidade de implementar a apropriação da força hidráulica dos rios para produção de energia elétrica. A produção de eletricidade a partir dos rios é vista como um recurso muito mais poderoso do que o sistema vigente, as usinas térmicas. No ano seguinte, informava que o serviço continuava nas mãos da mesma empresa e que o chamamento feito pela prefeitura para construção de uma usina hidroelétrica havia recebido apenas uma proposta que foi recusada. Dizia ainda, que a Prefeitura de Curitiba, empenhada em resolver o problema do fornecimento da energia elétrica,

(...) adquiriu pela importância de 500:000\$000 as quedas d'água existente no Rio Capivary, municípios de Campina Grande e Bocayuva, com capacidade de 30.000 cv na máxima estiagem e assim aparelhada pretende interessar todos os nossos industriaes na organização de uma Sociedade anonyma que tome a seu cargo a construcção da usina hydro-eletrica e sua exploração industrial. ${ }^{38}$

O rio é recortado e, uma de suas características, as quedas d'água, torna-se mercadoria. Não se trata especificamente do "acidente altimétrico", nos termos da época, mas sim a capacidade de produção de energia a partir da transformação da força hidráulica gerada pelo movimento da água. De qualquer forma, uma das particularidades naturais de um rio, começava a obter um significado inédito. Os rios passariam a ser explorados em busca de locais propícios para produzir energia elétrica. A valorização,

36 CAMARGO, Affonso Alves. Mensagem dirigida ao Congresso Legislativo do Estado pelo presidente ao instalar a 1 a Sessão da 14a Legislatura em 01/02/1918, p.32.

37 ROCHA, Caetano Munhoz da. Mensagem ao Congresso Legislativo do Paraná ao installar-se a 1a Sessão da 18ª Legislatura em 01/02/1926. Curitiba: s.ed., 1926, p.126. (grifos nossos)

38 ROCHA, Caetano Munhoz da. Mensagem ao Congresso Legislativo do Paraná ao installar-se a 2a Sessão da 19a Legislatura em 01/02/1927. Curitiba: s.ed., 1927, p.132. (grifos nossos) 
naquele momento, dessa característica natural dos rios pode ser avaliada pelos valores envolvidos na negociação de "compra das quedas d'água do rio Capivari". Considerando o valor pago pela prefeitura de Curitiba pelas "quedas" d'água, 500 contos de réis, percebe-se a grande importância atribuída a uma característica de um rio. Recorde-se que a ponte de 184 metros sobre o rio Paranapanema custou aproximadamente 100 contos ou que a arrecadação total de impostos do Estado 1924/1925 foi de cerca de 18.500 contos. Portanto, o valor pago reflete uma expectativa dos proprietários e dos administradores do Paraná, das perspectivas de utilização dos rios por essa nova demanda: a transformação da energia hidráulica em energia elétrica. Assim, não só as novas formas de percepção dos rios apareciam nas projeções governamentais, mas circulava, também, de modo mais amplo no social, pois envolveu no negócio proprietários privados de áreas de terra onde estavam localizadas as "quedas d'água".

No ano de 1929, na gestão de Afonso Alves Camargo, foi promulgado o decreto 1045 de 16 de julho, que determinava as bases para a exploração e instalação de usinas hidroelétricas no Estado. Já com um novo concessionário do serviço, a Empresas Elétricas Brasileiras S/A que organizou a Companhia Força e Luz do Paraná, foi assinado um contrato que a obrigava a construir uma "(...) usina para geração de energia eléctrica por força hydráulica (...)" no prazo máximo de 3 anos. ${ }^{39}$

No ano seguinte, o presidente informava que já havia sido feito os serviços de reconhecimento e que tinha sido escolhido o rio São J oão, no município de São J osé dos Pinhais para a construção da "usina hydro-elétrica". Foi decidido que seria construída uma barragem distante 45 quilômetros da cidade de Curitiba e uma usina que seria alimentada por um condutor. A usina seria localizada com uma diferença de altitude de 308 metros a menos. ${ }^{40} 0$ presidente esperava que ainda no ano de 1931 a usina seria inaugurada, o que de fato ocorreu. Estava inaugurado, assim, um período de intervenção humana nos rios do Paraná que se pode denominar de a "era das barragens".

As transformações ocorridas no âmbito da ação estatal, nos anos 1930 e 1940, são bastante conhecidas e debatidas pela historiografia. Uma das características das mudanças, que encontra consenso entre a maioria dos analistas, foi o caráter de aumento da intervenção estatal em todos os aspectos da sociedade, marcando o surgimento do estado interventor. Foi um fenômeno que ating iu o mundo todo, assumindo diversas nuances em relação às classes sociais e perfis políticos da constituição dos estados-

39 CAMARGO, Affonso Alves. Mensagem dirigida ao Congresso Legislativo o Estado pelo presidente ao installar-se a 2 a Sessão da 19a Legislatura em 01/02/1929. Curitiba: s.ed., 1929, p.88.

40 CAMARGO, Affonso Alves. Mensagem dirigida ao Congresso Legislativo o Estado pelo presidente ao installar-se a 1a Sessão da 20ㅡㅡㄴ Legislatura em 01/02/1930. Curitiba: s.ed., 1930, p.74-75. 
nacionais. A palavra planejamento passaria a fazer parte do vocabulário dos governantes desse perío do em diante. ${ }^{41}$ No Paraná, o governador Manoel Ribas, em 1935, com o intuito de "racionalizar" a administração pública e obter "maior produtividade dos funcionários", além de outras expectativas, solicitou que o "Instituto de Organização Racional do Trabalho (IDORT) de São Paulo, a maior e a mais completa organização dessa natureza no país se incubisse [sic] desse serviço no Governo do Paraná". ${ }^{42} 0$ IDORT não pode atender prontamente o pedido, o governador recorreu, então, aos peritos ingleses Mac Auliffe, Davis, Bell e Cia. ${ }^{43}$ Finalmente, o IDORT enviou um técnico para realizar os levantamentos necessários para apresentação de um "(...) plano de organização calcado em princípios racionais". ${ }^{44}$ Essa passagem demonstra, resumidamente, a circulação do ideário de "racionalização" pelos vários órgãos da administração pública brasileira, que provocou mudanças importantes nas relações estado/natureza, ou especificamente, entre o governo do Estado e os rios.

A intervenção direta do aparelho burocrático do Estado do Paraná nos cursos d'água para aproveitamento da energia hidráulica tinha sido insignificante até o final dos anos de 1930, limitando-se, como visto acima, a regulamentar a "instalação hidroelétricas nos rios do Estado". A partir desse período surgiu um movimento de mudanças dessa perspectiva, iniciado ainda na década de 1940, com uma primeira fase de planejamento das intervenções.

Em 1942, o interventor Manoel Ribas informava no seu relatório a Getúlio Vargas que o "aproveitamento da energia hidráulica", apesar da existência de um contrato com a Companhia Força e Luz do Paraná desde 1928, “(...) só foi levada a efeito a construção de uma usina, a de "Chaminé", com aproveitamento das águas do rio São J oão, no Município de São J osé dos Pinhais". ${ }^{45}$ Portanto, a apropriação dos rios para a produção de energia elétrica ainda era uma atividade privada.

41 Para uma análise de caráter mundial, ver HOBSBAWM, Eric. J . O breve século XX. 1914-1987. São Paulo: Cia das Letras, 1995; e um bom resumo, para o Brasil, ver CAPELATO, Maria H. O Estado novo: o que trouxe de novo? In: FERREIRA, J orge e DELGADO, Lucilia de Almeida. (orgs.) O tempo do nacional-estatismo: do início da década de 1930 ao apogeu do Estado Novo. Rio de J aneiro: Civilização Brasileira, 2003 e D'ARAUJ O, Maria Celina. Estado, classe trabalhadora e políticas sociais. In: FERREIRA, J orge e DELGADO, Lucilia de Almeida. (ed.) 0 tempo do nacional-estatismo: do início da década de 1930 ao apogeu do Estado Novo. Rio de J aneiro: Civilização Brasileira, 2003.

42 RIBAS, Manoel. Mensagem apresentada pelo governador do Estado a Assembléia Legislativa ao installar-se a $2^{\underline{a}}$ Sessão da 1aㅡ Legislatura da 2a República em 01/09/1936. Curitiba: Empresa Gráfica Paranaense, 1936, p.60. Sobre - IDORT e "a racionalização da sociedade brasileira" através de pressupostos científicos como política do Estado ver: ANTONACCI, M. A. M. A vitória da razão? São Paulo: Marco Zero, 1993.

43 RIBAS, Manoel. Mensagem apresentada pelo governador do Estado a Assembléia Legislativa ao installar-se a $2^{\underline{a}}$ Sessão da 1a Legislatura da 2a República em 01/09/1936, p.60.

44 RIBAS, Manoel. Mensagem apresentada pelo governador do Estado a Assembléia Legislativa ao installar-se a $2^{\underline{a}}$ Sessão da 1aㅡegislatura da 2a República em 01/09/1936, p.60.

45 RIBAS, Manoel. Relatório enviado ao Presidente da República relativo a administração do Interventor Federal no Estado do Paraná nos exercícios de 1940/1941. Curitiba: mimeo, 1942, p.13. 
O planejamento, ou a planificação, apareceria com força nos discursos políticos dos administradores no final da década de 1940, em especial a partir do mandato do Governador Moyses Lupion. Esse governador apresentou, em uma das suas Mensagens, uma Planificação de Obras, com a finalidade de atingir uma "planificação inteligente". ${ }^{46}$ Esse planejamento mudaria significativamente a relação da administração pública com os rios do Estado. Em função da crescente demanda pela energia elétrica, o governo passaria a projetar intervenções cada vez maiores nos cursos d'água do território paranaense:

No que à energia elétrica se refere, não são menos clamantes as nossas necessidades. Como todas as soluções anteriores se fizeram sem obedecer a nenhum esquema de conjunto (...) e foram antes iniciativas dispersas de municípios (...) aceitando soluções quase sempre precaríssimas de emergência (...) chegamos a um momento em que nos é forçoso mudar de direção. ${ }^{47}$

A nova direção proposta, tendo como base a idéia de planejamento racional, passaria a intervir sobre o território paranaense utilizando-se de referenciais e aspectos geográficos até então não privilegiados. 0 mesmo espaço geográfico, que vinha sendo pensado em termos de re-ocupação e aproveitamento de seus recursos naturais, especialmente as florestas e as terras agriculturáveis, passava a ser pensado em termos de organização de uma "rede de produção e distribuição de energia elétrica". Havia agora, além das redes técnicas de estradas, as redes de distribuição de eletricidade.

A importância que a energia elétrica havia assumido no período é perceptível em dois novos argumentos fundados na demanda dessa técnica de fornecimento de energia; o primeiro é uma classificação em termos "civilizatórios" ou de desenvolvimento, o segundo, pauta-se na importância dos recursos naturais aproveitáveis. No primeiro, a análise do governador, após constatar a fraca oferta de energia elétrica, lança mão de um padrão comparativo, regiões mais ou menos "densamente eletrificadas" para fazer projeções das necessidades de expansão da produção. ${ }^{48}$

Em relação ao segundo, a natureza dos rios existentes no Estado, que no passado havia impedido a realização de outra projeção, a rota fluvial com destino ao Mato Grosso, aparece agora como riqueza, promovendo 0 Estado ao primeiro lugar em uma comparação com outros Estados brasileiros: "Para bem compreendermos a nossa situação, paralelamente a esses

46 LUPION, Moyses. Mensagem apresentada à Assembléia Legislativa do Estado por ocasião da abertura da Sessão Legislativa de 1948. Curitiba: s.ed, 1948, p.06.

47 LUPION, Moyses. Mensagem apresentada à Assembléia Legislativa do Estado por ocasião da abertura da Sessão Legislativa de 1948, p.08.

48 LUPION, Moyses. Mensagem apresentada à Assembléia Legislativa do Estado por ocasião da abertura da Sessão Legislativa de 1948, p.09. 
fatos [a produção e consumo de energia elétrica no Paraná], ponhamos o outro de que o Paraná é o primeiro Estado do Brasil em fôrça hidráulica, podendo contar com 350 quedas dé água de uma certa importância". ${ }^{49}$ Os rios e suas características assumiam claramente um novo significado para as autoridades do Estado. Em outros termos, o Estado do Paraná seria rico por ter em seu território rios que possuíam uma grande quantidade de locais propícios ao aproveitamento da energia hidráulica. Dois desdobramentos das características naturais dos rios do território paranaense: primeiro a valorização para produção de energia elétrica e, segundo, a partir da natureza a construção de um discurso de fortalecimento de identidade em relação às outras unidades administrativas.

O final da década de 1940, aparece como o período no qual foram definidos, também, os principais rios e locais onde poderiam ser construídas usinas hidrelétricas. Essa definição estava explicitada claramente nos projetos do governador Moyses Lupion para organizar a produção e distribuição de energia elétrica no "território" do Paraná, o que ele chamou de "Plano Hidro-elétrico Paranaense". Até esse momento havia, em operação no Estado, 22 hidroelétricas, públicas e privadas, quase todas de pequena capacidade, instaladas em pequenos rios e quedas d'água, com exceção da mencionada Usina Chaminé, no rio São J oão em São J osé dos Pinhais. ${ }^{50}$

A partir dessa gestão, o Estado passou a intervir diretamente na organização, produção e distribuição de energia elétrica, com a criação do Serviço de Energia Elétrica do Estado em 1947, transformado em Departamento de Águas e Energia Elétrica em 1948, como "pessoa jurídica, autonomia administrativa e financeira", o que seria a origem da COPEL - Companhia Paranaense de Energia Elétrica.

O aproveitamento dos rios para geração de energia elétrica não era uma especificidade do Estado do Paraná, mas seguia uma tendência nacional. O Plano Hidro-elétrico Paranaense, de Moyses Lupion, seguia as determinações e planejamento realizados pelo Governo Federal, obedecendo as recomendações da "(...) Comissão Técnica do Planejamento de Energia Elétrica, em 20 Congresso Brasileiro de Energia e Indústria" que previa a ação do Estado na ausência da iniciativa particular e o estabelecimento de "redes de coordenação". Seguindo essa diretriz, o governo paranaense dividiu 0

território em três sistemas elétricos, o do sul, o n. 1, o do norte, n. 2, e o do oeste, n. 3 (...) sendo cada sistema dividido em grupos e cada grupo em centros, afim

49 LUPION, Moyses. Mensagem apresentada à Assembléia Legislativa do Estado por ocasião da abertura da Sessão Legislativa de 1948, p.09.

50 LUPION, Moyses. Mensagem apresentada à Assembléia Legislativa do Estado por ocasião da abertura da Sessão Legislativa de 1948, p.41. 
de melhor acentuar a tendência de uma centralização reguladora para a coordenação das operações de geração e transmissão de energia elétrica. ${ }^{51}$

Em cada um desses três sistemas no qual o território foi dividido pelo planejamento do governo, o Estado se propunha a criar um “(...) poderoso centro produtor de energia hidro-elétrica para atender a eventual e intensiva industrialização do Estado". Esses centros produtores poderosos seriam:

Para suprir as deficiências de energia elétrica do primeiro sistema [litoral] pretende - Estado aproveitar o centro hidro-elétrico das bacias Capivari-Cachoeira com potência instalada superior a 250.000 H.P. no município de Antonina e o Salto Grande, no rio Iguaçu a $5 \mathrm{~km}$ de Porto Almeida, com potência instalada de cerca de 50.000 H.P. Para o sistema 02, do norte do Estado, prevê-se o aproveitamenteo do Salto Capivari (Capivara) no Rio Paranapanema, município de Porecatú, com potência instalada de ca.65.000 HP. ${ }^{52}$

O território passava a ser organizado em função da existência de características naturais dos rios, locais propícios a construção de barragem. Assim como no caso dos projetos ferroviários, examinados acima, os rios tornavam-se determinantes nas formas de planejamento do território, da apropriação de seus recursos naturais. Os rios não eram mais estradas, não se procurava mais povoar o território a partir de suas margens; suas quedas, secas ou enchentes não mais atrapalhariam a navegação. Os estudos não mais seriam realizados para verificar o caminho mais longo ou mais curto, ou para verificar os obstáculos a navegação. Os rios agora contavam pela capacidade instalada de "Hs.Ps". Novos tempos, novas linguagens de aferição da possibilidade de apropriação da natureza. São os tempos da sociedade industrial. ${ }^{53}$

O Plano Hidro-Elétrico Paranaense necessitava, para sua realização, estudos das condições dos rios, das suas "reservas hidráulicas e do seu aproveitamento hidro-elétrico". Iniciava-se, por esse motivo, uma nova fase de investigação e de estudos dos rios, envolvendo diversos órgãos do governo federal e estadual, diferentes repartições e instalações em vários locais do Estado. Havia em 1949, segundo o governo, “(...) 38 estaçoes plúvio-fluviométricas da Divisão de Águas do Ministério da Agricultura; 30 Postos Pluviométricos distribuídos em estações ferroviárias, fazendas e outras localidades" cujos dados foram analisados e estudados, e "(...) 07

51 LUPION, Moyses. Mensagem apresentada à Assembléia Legislativa do Estado por ocasião da abertura da Sessão Legislativa de 1948, p.42.

52 LUPION, Moyses. Mensagem apresentada à Assembléia Legislativa do Estado por ocasião da abertura da Sessão Legislativa de 1948, p.46.

53 Ver SEVCENKO, Nicolau. Introdução. "O prelúdio republicano, astúcias da ordem e ilusões do progresso". In: NOVAIS, Fernando. (ed.) História da vida privada no Brasil República: da Belle Époque 'a Era do Rádio (v.3). São Paulo: Cia. das Letras, 1998, p.7-48. 
bacias hidrográficas e 121 acidentes altimétricos, com potência hidráulica total de 4.382 .838 H.P". ${ }^{54}$

Planejava-se realizar investigações, ou já estavam sendo realizados estudos, nos seguintes lugares: “Capivara, no rio Paranapanema, município de Porecatú; Salto Grande, no rio Iguaçu, município de União da Vitória; Rio Ivai; Rio Corumbataí; Rio Pirapó; Rio Campo Mourão; Rio Morato, no município de Guarequeçaba; Rio Ponta-Grossa, no município de Cerro Azul; Rio Laranjinhas, no município de Ribeirão do Pinhal; Rio Tacaniça, no município de Rio Branco do Sul; (...)". ${ }^{55}$ Como acontecia com a necessidade de construir pontes, novamente, os nomes dos rios aparecem com força nas falas das autoridades, revelando a sua existência e importância. A quantidade de lugares mencionados evidencia a projeção futura das intervenções nos rios do Estado.

A nova perspectiva que os rios estavam assumindo partir dos anos de 1940 nas projeções das autoridades administrativas do Paraná, não era específica ao Estado, mas estava presente em todos os espaços, acompanhando as transformações pelas quais o Estado e a sociedade no Brasil passaram durante e no após guerra. Nas Mensagens dos governadores do período percebe-se facilmente a presença das diretrizes do governo federal, especialmente, na temática examinada. Havia um Plano Nacional de Eletrificação, formulado pelo Conselho Federal de Comércio Exterior. Na análise do governador Moyses Lupion, essas diretrizes eram decorrentes de uma série de iniciativas, que ele chamou de "movimento pela expansão do abastecimento hidro-elétrico", o qual teria iniciado propriamente com o Código Nacional de Águas de 1937, depois com a criação do Conselho Nacional de Águas e Energia Elétrica, em 1939 e, finalmente, o Plano Nacional de Eletrificação, em 1949. Esse plano possuía várias diretrizes, entre as quais, a de número 03: Política de utilização das fontes hidráulicas de energia. ${ }^{56} \mathrm{~A}$ crescente demanda por energia elétrica impulsionada pela urbanização e crescimento do parque industrial brasileiro impunha o aumento de fontes de energia, no caso, com a utilização dos rios.

$\mathrm{Na}$ última mensagem de seu mandato, o governador Moyses Lupion, descreveu longamente suas ações relacionadas ao fornecimento de energia elétrica. Na parte "Preliminares estatísticos" encontra-se os resultados dos estudos realizados. Na avaliação desses resultados, o governador chega a uma conclusão ufanística: "O Paraná é o primeiro Estado do Brasil em fôrça hidráulica, podendo contar com cerca de 350 quedas de certa importân-

54 LUPION, Moyses. Mensagem apresentada à Assembléia Legislativa do Estado por ocasião da abertura da Sessão Legislativa de 1949. Curitiba: s.ed, 1949, p.67.

55 LUPION, Moyses. Mensagem apresentada à Assembléia Legislativa do Estado por ocasião da abertura da Sessão Legislativa de 1949, p.67.

56 LUPION, Moyses. Mensagem apresentada ao povo do Paraná pelo governador do Estado, ao término do seu mandato em 1950. Curitiba: s.ed., 1950, p.165-166. 
cia". ${ }^{57}$ Desses 350 "acidentes altimétricos" já havia sido possível determinar a potência de 121, descritos na mensagem detalhadamente por bacia e por rios. Por exemplo, na Bacia do Rio Iguaçu, havia 31 saltos com capacidade de 1.568.787 HP. Na Bacia do rio Ivai, outros 28 saltos tinham capacidade avaliada em 107.044 HP. Já na bacia do Litoral, seriam 23 acidentes e a capacidade estimada fora de 175.000 HP. No rio Paraná e sua bacia, foram encontrados apenas 05 saltos distribuídos em 05 rios para 0 aproveitamento "hidro-elétrico". 0 mais famoso deles era o "Salto Sete Quedas". A capacidade total estimada para essa bacia era de 12.011.378 HP. Na bacia do Rio Paranapanema, composta por 05 rios, incluindo o próprio Paranapanema, foram encontrados 13 saltos que poderiam produzir $248.000 \mathrm{HPs}$. Na Bacia do Ribeira, os estudos apontaram 10 acidentes e a capacidade de geração de $176.000 \mathrm{HP}$ e, finalmente, a bacia do Tibagi, composta por 07 rios foram avaliados 18 saltos com a capacidade de $108.000 \mathrm{HP}^{58} \mathrm{O}$ mapeamento realizado pelo Estado, adotando a perspectiva de zoneamento por bacia hidrográfica, revela uma nova perspectiva de apropriação do natural para 0 planejamento de ações governamentais e, também, a extensão dos estudos que estavam sendo realizados.

Algumas dessas quedas e locais estudados ou apontados nos anos de 1940 foram efetivamente, nas décadas seguintes, utilizad os para produção de energia elétrica como, por exemplo, o de Capivara (Capivara) ${ }^{59}$, Salto Grande (Salto Grande), etc. Alguns, como os do rio Tibagi, ficaram, até a atualidade, livres de barragens, embora desde os anos 80 a COPEL tenha retomado os estudos nesse rio, definindo quase que os mesmos locais, para futuras barragens.

Até a "era das grandes barragens" as relações que o governo do Estado havia mantido, por quase cem anos, com os rios do território paranaense pouco, ou quase nenhuma alteração havia provocado em suas características. As poucas marcas, objetos técnicos, resultantes da ação do Estado que sobreviveram eram as pontes, pontilhões, algumas pequenas barragens em rios menores, portos, balsas, etc.

As grandes barragens alterariam completamente essa dinâmica e deixariam para sempre a marca da ação humana gravada em suas quedas, margens e cursos d'água. As enormes montanhas de concreto barrando 0 livre passar das águas, os novos peixes introduzidos, as milhares de pessoas desalojadas, as novas dinâmicas de interação com as águas são evidências

57 LUPION, Moyses. Mensagem apresentada ao povo do Paraná pelo governador do Estado, ao término do seu mandato em 1950, p.167.

58 LUPION, Moyses. Mensagem apresentada ao povo do Paraná pelo governador do Estado, ao término do seu mandato em 1950, p.167-170.

59 A barragem na queda, propriamente uma grande "corredeira', de Capivara começou a ser construída no início dos anos de 1970 e a inauguração da hidroelétrica ocorreu em 1978, sendo a maior barragem do rio Paranapanema, cujo lago ocupa $515 \mathrm{~km} 2$, podendo gerar até $619 \mathrm{mw}$ de energia. Ver Informações constantes no site da empresa controladora Duke Energy. Ver http://www.duke-energy.com.br/PT/Usinas/uhe_capivara.asp?id=1_8. 
dessa interação entre homens e natureza no território paranaense. As usinas hidroelétricas são, atualmente, partes constituintes das paisagens dos rios, visíveis muito além do que os olhos podem alcançar.

\section{Conclusão}

O exame das Mensagens dos presidentes da Província e do Estado, do período de 1853-1949, demonstra a riqueza dessa fonte para os estudos de história ambiental devido a periodicidade constante, a abrangência dos assuntos tratados e, em especial, os anexos contendo relatórios de expedições, estudos e análises de profissionais como engenheiros, botânicos, médicos, etc.

No caso do presente artigo, permitiu acompanhar as mudanças significativas existentes nas relações entre a administração estadual e os rios do território do Paraná, através do que poderia ser denominado, com as ressalvas de temporalidade necessária, como "políticas de governo". Evidenciadas por ações concretas ou por projetos de aproveitamento, as relações se configuram ora de forma clara e visível, como nos projetos de "hidrovias" ou como examinado, na apropriação para produção de energia elétrica, ora, os rios de forma "oculta", aparecem através das ações para sua transposição, como a construção de pontes, balsas ou pontilhões. De uma forma ou de outra, as ações governamentais respondem as demandas da sociedade, permitindo, assim, concluir que as formas de apropriação dos rios evidenciadas pelos documentos oficiais representam interesses concretos de grupos sociais.

As tecnologias, ou os objetos técnicos, configuram-se como demandas concretas da sociedade pelo aproveitamento, ou transformação, das condições naturais existentes. No caso dos rios, no século XX, em especial na segunda metade desse século em diante, conforme foi argumentado nesse artigo, o surgimento da tecnologia da energia elétrica e, depois, a transformação da energia hidráulica dos cursos d'água em eletricidade, marcaram profundamente o relacionamento homem $x$ natureza no Brasil. $\mathrm{A}$ força dessa interdependência, praticamente obscurece as demandas anteriores e, muitas vezes, também as atuais, como o desafio do fornecimento de "água potável" no século XXI. 